ГОСУДАРСТВЕННАЯ ВЛАСТЬ. ЗАКОНОДАТЕЛЬНЫЙ ПРОЦЕСС. КОНСТИТУЦИОННОЕ ПРАВО. ПУБЛИЧНОЕ УПРАВЛЕНИЕ. МЕСТНОЕ САМОУПРАВЛЕНИЕ

УДК 342.734

DOI https://doi.org/10.17308/vsu.proc.law.2021.2/3384

\title{
НЕКОТОРЫЕ ПРОБЛЕМНЫЕ АСПЕКТЫ ПРАВОВОГО РЕГУЛИРОВАНИЯ ВОПРОСОВ ПОВЫШЕНИЯ ЗАИНТЕРЕСОВАННОСТИ ГРАЖДАН В ЗДОРОВОМ ОБРАЗЕ ЖИЗНИ
}

\author{
Н. В. Соколова \\ Челябинский государственныцй университет
}

3. Н. Черных

Шадринский государственный педагогический университет

Поступила в редакцию 15 января 2021 г.

\begin{abstract}
Аннотация: поднилается проблела правового обеспечения конституиионного права на охрану и укрепление здоровья населения, предлагаются различные методь повышения заинтересованности граждан в здоровол образе жизни и повышении уровня фбизической активности.

Ключевые слова: здоровый образ жизни, фбизическая культура, повышение заинтересованности в занятиях фбизкультурой, трудовые отношения, образование.
\end{abstract}

Abstract: the article raises the problem of the legal provision of the constitutional right to protect and strengthen the health of the population, proposes various methods to increase the interest of citizens in a healthy lifestyle and increase the level of physical activity.

$\sim \quad$ Key words: healthy lifestyle, physical culture, increasing interest in physical education.

Вопросам здоровья населения со стороны государства уделяется большое внимание. Право каждого на охрану здоровья и медицинскую помощь, а также финансирование федеральных программ охраны и укрепления здоровья населения, поощрение деятельности, способствующей укреплению здоровья человека, развитию фризической культуры и спорта, экологическому и санитарно-эпидемиологическому благополучию населения продекларировано в ст. 41 Конституции РФ, а также подкреплено правом на благоприятную окружающую среду (ст. 42)1․

Несмотря на продекларированные в Конституции РФ права граждан, следует подчеркнуть, что, к сожалению, в настоящее время невозможно утверждать, что у населения сформировано стремление вести исключительно здоровый образ жизни. В связи с этим представляет-

${ }^{1}$ Конституция Российской Федерации : принята всенародным голосованием 12 декабря 1993 г. (с поправками от 30 декабря 2008 г., 5 фревраля, 21 июля 2014 г., 1 июля 2020 г.). Доступ из справ.-правовой системы «КонсультантПлюс».

(C) Соколова Н. В., Черных 3. Н., 2021 
ся целесообразным предпринять меры к совершенствованию государственной политики в этой сфрере с целью повышения заинтересованности людей в сохранении и преумножении своего физического здоровья, в том числе и доступными правовыми средствами.

Следует констатировать, что в действующих нормах фредерального законодательства этот вопрос не обделен вниманием. В частности, в п. 6 ст. 2 Федерального закона «Об основах охраны здоровья граждан в Российской Федерации» предусматривается, что «профилактика - это комплекс мероприятий, направленных на сохранение и укрепление здоровья и включающих в себя фрормирование здорового образа жизни, предупреждение возникновения и (или) распространения заболеваний, их раннее выявление, выявление причин и условий их возникновения и развития, а также направленных на устранение вредного влияния на здоровье человека фракторов среды его обитания». В ст. 4 этого закона закреплены основные принципы охраны здоровья, в том числе приоритет профиллактики в сфере охраны здоровья. В п. 8 ст. 16 анализируемого закона вопросы организации «осуществления мероприятий по профилактике заболеваний и формированию здорового образа жизни у граждан, проживающих на территории субъекта Российской Федерации отнесены к полномочиям органов государственной власти субъектов Российской Федерации в сфере охраны здоровья», а п. 6 ст. 17 - «реализация на территории муниципального образования мероприятий по профилактике заболеваний и фрормированию здорового образа жизни в соответствии с законом субъекта Российской Федерации»².

С точки зрения пропаганды здорового образа жизни, в том числе физической культуры и спорта, направленной на формирование в обществе негативного отношения к наркомании, следует отметить Федеральный закон от 8 января 1998 г. № 3-ФЗ «О наркотических средствах и психотропных веществах", в ст. 53.2 которого предусмотрены полномочия фредеральных органов исполнительной власти в сфере профилактики незаконного потребления наркотических средств и психотропных веществ, наркомании, к которым, в частности, отнесено «ведение пропаганды здорового образа жизни и нетерпимого отношения к незаконному потреблению наркотических средств и психотропных веществ, наркомании» ${ }^{3}$.

О здоровом образе жизни и реализации «мер по гигиеническому воспитанию и обучению населения, пропаганде здорового образа жизни» упоминается и в Федеральном законе «О санитарно-эпидемиологи-

2 Об основах охраны здоровья граждан в Российской Федерации : фредер. закон от 21 ноября 2011 г. № 323-ФЗ (в ред. от 22.12.2020). Доступ из справ.-правовой системы «КонсультантПлюс».

${ }^{3} \mathrm{O}$ наркотических средствах и психотропных веществах : федер. закон от 8 января 1998 г. № 3-ФЗ (в ред. от 26.07.2019). Доступ из справ.-правовой системы «КонсультантПлюс». 


\section{Вестник ВГУ. Серия: Право}

ческом благополучии населения» ${ }^{4}$, о распространении «санитарно-гигиенических знаний среди несовершеннолетних, их родителей или иных законных представителей, а также пропаганде здорового образа жизни» - в Федеральном законе «Об основах системы профилактики безнадзорности и правонарушений несовершеннолетних ${ }^{5}$.

Обращение к Федеральному закону «Об образовании» позволяет констатировать, что в силу положений подп. 10.1, 15, 16 п. 3 ст. 28 в обязанности образовательной организации входит «поощрение обучающихся ... за успехи в учебной, физкультурной, спортивной, общественной, научной, научно-технической, творческой, экспериментальной и инновационной деятельности и создание необходимых условий для охраны и укрепления здоровья, организации питания обучающихся и работников образовательной организации, а также создание условий для занятия обучающимися фризической культурой и спортом». Причем в соответствии с подп. 4, 5, 7 п. 1 ст. 41 данного закона охрана здоровья обучающихся, наряду со многими другими фракторами, включает также «пропаганду и обучение навыкам здорового образа жизни, требованиям охраны труда и организацию и создание условий для профилактики заболеваний и оздоровления обучающихся, для занятия ими физической культурой и спортом, профрилактику и запрещение курения, употребления алкогольных, слабоалкогольных напитков, пива, наркотических средств и психотропных веществ, их прекурсоров и аналогов и других одурманивающих веществ» ${ }^{6}$.

К фредеральным законам, направленным на формирование здорового образа жизни и повышение ответственности за собственное здоровье у граждан России, необходимо также отнести: «О качестве и безопасности пищевых продуктов», «Об иммунопрофилактике инфекционных

болезней», «О предупреждении распространения в Российской Феде일 рации заболевания, вызываемого вирусом иммунодефицита человека (ВИЧ-инфекции)», «О предупреждении распространения туберкулеза в Российской Федерации» и др.

Анализ правового регулирования исследуемой проблемы позволяет констатировать, что федерального закона, в котором предусматривалось бы комплексное регулирование всех необходимых аспектов обеспечения формирования у населения России здорового образа жизни, к сожалению, не принято и вряд ли может быть принято из-за очень широкого спектра проблем, которые требуют специфического подхода.

${ }^{4}$ О санитарно-эпидемиологическом благополучии населения : фредер. закон от 30 марта 1999 г. № 52-ФЗ (в ред. от 13.07.2020). Доступ из справ.-правовой системы «КонсультантПлюс».

${ }^{5}$ Об основах системы профилактики безнадзорности и правонарушений несовершеннолетних : федер. закон от 24 июня 1999 г. № 120-ФЗ (в ред. от 24.04.2020). Доступ из справ.-правовой системы «КонсультантПлюс».

${ }^{6}$ Об образовании в Российской Федерации : фредер. закон от 29 декабря 2012 г. № 273-ФЗ (в ред. от 08.12.2020). Доступ из справ.-правовой системы «КонсультантПлюс». 
Попробуем сконцентрироваться на одном из чрезвычайно важных аспектов, способствующих укреплению здоровья населения, формированию здорового образа жизни граждан страны - физической культуре.

Обращение к «Информационно-коммуникационной стратегии по формированию здорового образа жизни, борьбе с потреблением алкоголя и табака, предупреждению и борьбе с немедицинским потреблением наркотических средств и психотропных веществ на период до 2020 года", в которой провозглашено, что "сохранение и укрепление здоровья населения на основе формирования здорового образа жизни и обеспечения качества и доступности медицинской помощи населению является приоритетом государственной политики в Российской Федерации», одной из важных задач признано "повышение уровня физической активности, приверженности рациональному питанию, снижение уровня психоэмоциональной нагрузки у населения Российской Федерации». Следует отметить, что в качестве показателя эффективности реализации Стратегии предусматривается снижение распространенности низкой физической активности среди взрослого населения с 40 до $36 \%$.

Постановлением Правительства РФ от 15 апреля 2014 г. № 302 была утверждена государственная программа Российской Федерации «Развитие физической культуры и спорта». В данном документе выделена подпрограмма «Развитие физической культуры и массового спорта», в которой планируется увеличение доли населения, занятого в экономике, занимающегося физической культурой и спортом, увеличить с 13,5 до $25 \%$, учащихся и студентов - с 57 до $80 \%$. Кроме того, предусматривается привлечь к этому важному делу социально ориентированные некоммерческие организации, оказывающие услуги в области физической культуры и спорта и поднять их удельный вес до 3 \%, долю сельского населения, систематически занимающегося физической культурой и спортом, в общей численности населения Российской Федерации в возрасте от 3 до 79 лет поднять с 26 до $29,3 \%{ }^{8}$.

До распада Советского Союза, когда занятия в спортивных секциях не были поставлены на коммерческую основу, подавляющее большинство граждан страны всех возрастов активно занимались физической культурой. Приходя в спортивные секции в раннем возрасте, люди привыкали к активному образу жизни и считали физическую

${ }^{7}$ Об утверждении Информационно-коммуникационной стратегии по формированию здорового образа жизни, борьбе с потреблением алкоголя и табака, предупреждению и борьбе с немедицинским потреблением наркотических средств и психотропных веществ на период до 2020 года : приказ Министерства здравоохранения РФ от 30 сентября 2013 г. № 677. Доступ из справ.-правовой системы «КонсультантПлюс».

8 Об утверждении государственной программы Российской Федерации «Развитие фризической культуры и спорта» : постановление Правительства РФ от 15 апреля 2014 г. № 302 (в ред. от 23.11.2020). Доступ из информ.-правовой системы «Гарант». 


\section{Вестник ВГУ. Серия: Право}

активность совершенно естественной. Вынуждены констатировать, что убедить современное поколение в необходимости осознанного занятия физической культурой чрезвычайно непросто. Увы, упущено слишком многое. А главное, коммерциализация фризической культуры и спорта в условиях, когда более 20 млн человек или 15 \% населения имеют доходы ниже величины прожиточного минимума ${ }^{9}$, не является фрактором, повышающим заинтересованность посещения платных спортивных секций, а каждодневная культура занятий различными видами фризической активности в домашних условиях у молодого поколения, увы, не воспитана.

Чтобы хоть как-то нивелировать эту проблему и возвести здоровый образ жизни в статус главной ценности всех поколений, живущих в нашей стране, необходимо организовать комплексную работу, направленную на повышение значимости фризической культуры и спорта в формировании здорового образа жизни населения, для этого необходим полный комплекс: структурных, организационных, правовых, научно-методических мер.

Не должны оставаться в стороне от решения этой проблемы родители, которые, в первую очередь, должны закладывать основы здоровья и позитивного отношения к спорту у своих детей с раннего возраста. Ухудшение состояния здоровья нашей молодежи свидетельствует о необходимости решения этой проблемы ${ }^{10}$.

Не вызывает возражений мнение И. С. Кочетовой и Н. А. Усцелемовой, полагающих, что усилия государства, гражданского общества и каждого человека должны быть направлены:

- на повышенное внимание взрослых к здоровью детей;

- внедрение новых эфрфективных фрорм организации занятий фризической культурой, вызывающих интерес у молодежи;

- оздание отраслевых бюджетных, но качественных и гигиенических товаров для фризической культуры и спорта;

- строительство в учебных заведениях спортивных комплексов, в которых будут находиться тренажерные залы, бассейны и др. ${ }^{11}$

Для привлечения молодежи в возрасте 13-15 лет к физическому воспитанию необходимо:

1) вести пропаганду здорового образа жизни в школах и других образовательных учреждениях;

2) увеличить количество бесплатных спортивных секций и клубов;

9 У ровень бедности в России. URL: https://visasam.ru/russia/goroda/bednost-vrossii.html (дата обращения: 13.05.2020).

10 Финансирование фризической культуры и спорта. URL: http://isfic.info/ profsport/alfiz33.htm (дата обращения: 13.08.2020).

${ }^{11}$ См.: Кочетова И. С., Усцелелова Н. А. Популяризация спорта среди молодежи Челябинской области // Научное сообщество студентов XXI столетия. Гуманитарные науки : материалы XXVII Междунар. студ. науч.-практ. конф. Новосибирск, 2014. С. 324-328. 
3) увеличить строительство спортивных площадок возле жилых домов.

Если спортивные объекты станут более доступными, это позволит молодежи улучшить свои навыки фризической активности, в том числе и спортивные.

В национальном проекте предусматривается строительство различных спортивных объектов, но, к сожалению, для того чтобы в предлагающемся ритме мероприятий обеспечить все населенные пункты страны доступными для всех спортивными объектами, потребуется не один десяток лет, т. е. даже не одно поколение людей уйдет из жизни, не дождавшись выполнения этих благих пожеланий.

Еще П. Ф. Лесгафрт выступал за фризическое воспитание молодежи, вкладывая в его содержание развитие ума, уничтожение произвола в мыслях и действиях человека, уча его контролировать свое тело, для чего фризическое воспитание должно проводиться так же, как и умственное, на основе точно таких же методов ${ }^{12}$.

Думается, что для привлечения молодых людей в возрасте 16-24 лет к физической культуре и спорту было бы рационально организовывать:

1) эстафеты и спортивные соревнования в рамках населенных пунктов и привлекать к ним молодежь;

2) фрлешмобы на спортивную тематику;

3) встречи с известными спортсменами;

4) занятия фризической культурой и спортом в вузах и на рабочих местах.

Представляется целесообразным также и на уровне нормативно-правовых актов предусмотреть меры, способные заинтересовать в укреплении здоровья средствами физической активности молодое поколение, обучающееся в учебных заведениях разного уровня.

Анализ законодательства позволяет констатировать, что для повышения заинтересованности молодого поколения в здоровом образе жизни предпринимаются следующие меры правового регулирования. Так, согласно ст. 41 Федерального закона «Об образовании», охрана здоровья обучающихся включает в себя «пропаганду и обучение навыкам здорового образа жизни, требованиям охраны труда; организацию и создание условий для профилактики заболеваний и оздоровления обучающихся, для занятия ими фризической культурой и спортом»13. В ч. 2 ст. 28 Федерального закона «О физической культуре и спорте» подчеркивается, что организация фризического воспитания и образования в образовательных организациях включает в себя формирование «у обучающихся навыков физической культуры с учетом индивидуальных способностей и состояния здоровья, создание условий для вовлечения

12 См.: Лесгаббт П. Ф. Избранные труды. М., 1987. С. 360.

13 Об образовании в Российской Федерации : фредер. закон от 29 декабря 2012 г. № 273-ФЗ (в ред. от 08.12.2020). Доступ из справ.-правовой системы «КонсультантПлюс». 
обучающихся в занятия физической культурой и спортом и ответственного отношения родителей (лиц, их заменяющих) к здоровью детей и их физическому воспитанию» ${ }^{14}$.

В соответствии с п. 10.1 ч. 3 ст. 28 Федерального закона «Об образовании» для решения этой проблемы предусматривается право образовательной организации поощрять обучающихся в соответствии с установленными образовательной организацией видами и условиями поощрения за успехи в учебной, физкультурной, спортивной, общественной, научной, научно-технической, творческой, әкспериментальной и инновационной деятельности. Однако конкретные меры поощрения в законе не прописаны. Большинство образовательных организаций находятся на бюджетном финансировании, поэтому заведомо ограничены в финансовых возможностях поощрения обучающихся в занятиях физической культурой. Вынуждены констатировать, что любые поощрения требуют дополнительного, часто немалого финансирования, которое без вмешательства со стороны государства, основанного на нормах права, невозможно.

Правда, даже при таком скудном финансировании некоторые руководители образовательных учреждений находят способы решения финансовых вопросов. Так, опыт Шадринского филиала Тюменского государственного университета, существовавшего ранее, позволяет утверждать, что применявшиеся методы работы со студентами существенно влияли на повышение интереса студентов к здоровому образу жизни. Например, организовывались выезды со студентами на природу для участия в городских туристических слетах, в которых принимали участие даже студенты заочной формы обучения, традиционно завоевывавшие призовые места. Кроме того, студенты участвовали в городских и областных кроссах, в соревнованиях по разным видам 이 спорта и, несмотря на отсутствие у филиала своего спортивного зала, становились победителями и призерами соревнований различного уровня. Занятия физической культурой и спортом формировали также активную жизненную позицию обучающихся, что становилось катализатором их научно-исследовательской работы. В качестве поощрения лучших студентов руководство филиала применяло премирование путевками для отдыха за рубежами России.

Представляется целесообразным законодательно предусмотреть виды поощрения обучающихся за активное занятие физической культурой и спортом в процессе обучения для стимулирования их интереса к здоровому образу жизни, поскольку отсутствие стимулирующих факторов явно не способствует повышению заинтересованности обучающихся в физической активности.

Несмотря на стремление власти вновь внедрить в умы и настроения как подрастающего поколения, так и взрослого населения страны здо-

14 О фризической культуре и спорте : фредер. закон от 4 декабря 2007 г. №329Ф3 (в ред. от 08.12.2020). Доступ из справ.-правовой системы «КонсультантПлюс». 
рового образа жизни, тем не менее, каких-то реальных мер, направленных на повышение заинтересованности граждан страны в изменении ситуации в лучшую сторону на законодательном уровне, к сожалению, не предпринято. Хотя в ст. 30 Федерального закона «О физической культуре и спорте» предусматривается, что "в соглашения, коллективные договоры и трудовые договоры между работодателями, их объединениями и работниками или их полномочными представителями могут включаться положения: о создании работникам условий для занятий физической культурой и спортом, проведении фризкультурных, спортивных, реабилитационных и других связанных с занятиями граждан физической культурой и спортом мероприятий». Однако при отсутствии федеральных гарантий и собственных возможностей у подавляющего большинства работодателей предоставления "работникам и членам их семей возможности использовать объекты спорта, спортивное оборудование и инвентарь» работодатели предпочитают самоустраняться от решения этих вопросов. Как усматривается из Паспорта фредерального проекта «Формирование системы мотивации граждан к здоровому образу жизни, включая здоровое питание и отказ от вредных привычек», «доля граждан, систематически занимающихся фризической культурой и спортом», должна повышаться «благодаря модельнылм мунииипальнылм и корпоративнылм програлмлал»"15.

С учетом современного положения в экономической сфере, связанной с пандемией, надеяться на решение этими субъектами обозначенных в проекте задач вряд ли приходится.

Обращение к главе 28 ТК РФ позволяет выявить, что среди положений, предусматривающих гарантии и компенсации работающим, устанавливаются гарантии, в частности, при временной нетрудоспособности (ст. 183), при несчастном случае на производстве и профессиональном заболевании (ст. 184), для прохождения медицинского осмотра (ст. 185) и диспансеризации (ст. 185.1) и др. ${ }^{16}$ Однако каких-либо гарантий, заинтересовывающих работников в здоровом образе жизни, увы, не предусмотрено. Следует отметить, что, например, в случае дополнения главы 28 ТК РФ статьей, устанавливающей такие гарантии, заинтересованность населения к повышению уровня фризической активности явно повысится. Например, вполне уместна была бы такая формулировка:

Статья 185.2 ТК РФ. Гарантии работникал, ведушили здоровьй образ жизни

Работники, ведущие здоровый образ жизни и занилающиеся фбизической культурой, илеют право на получение колпенсации произведен-

15 Укрепление общественного здоровья : федер. проект «Демография : национальный проект» : утв. 24 декабря 2018 г. Советом при Президенте РФ по стратегическому развитию и национальным проектам. URL: https:/mintrud.gov. ru/ministry/programms/demography/4 (дата обращения: 05.11.2020).

16 Трудовой кодекс Российской Федерации : федер. закон от 30 декабря 2001 г. № 197-ФЗ (в ред. от 29.12.2020). Доступ из справ.-правовой системы «КонсультантПлюс». 
ных ими затрат на оплату предоставленных им услуг в размере, не превышаюшел среднего месячного заработка в год.

Работнику, занимающелуся фбизической культурой, предоставляется возможность освобождения от работы для занятий фбизической культурой на основании его письменного заявления на два часа в течение недели, время освобождения от работы согласовывается с работодателел.

Введение с января 2021 г. возможности получения налогового вычета за расходы на занятия физической культурой, к сожалению, не смогут кардинально изменить ситуацию в сторону повышения заинтересованности граждан в здоровом образе жизни, поскольку лишь в малой доле смогут сократить расходы, причем лишь работающего населения. А с учетом сложности получения налогового вычета и отсутствия у граждан навыков оформления налоговых документов вряд ли будет активно использоваться.

Представляется чрезвычайно интересным такой способ повышения заинтересованности граждан в повышении физической активности, который внедрен в Узбекистане, где каждый совершеннолетний житель страны может получить в качестве стимула за пройденные ежедневно 10000 шагов, установленные указом Президента страны, пусть не очень значительные, но все же дополнительные денежные суммы. Для этого требуется зарегистрироваться на сайте «Здоровый образ жизни», где и будет фиксироваться физическая активность каждого, а выплаты производятся на специальный электронный кошелек ${ }^{17}$. Деньги для осуществления этой инициативы планируется собирать в качестве дополнительного налога с производителей вредных для здоровья продуктов. Думается, что использование этого варианта решения проблеح мы, а также ужесточение требований к качеству продуктов питания вполне рационально было бы использовать и в российской практике, тем более что это позволит действительно заинтересовать все взрослое население страны в таком полезном для здоровья и законном способе повысить доходы семьи.

Предлагаемый путь решения этой проблемы позволит действительно повысить продолжительность здоровой жизни не до 67 лет, как указано в федеральном проекте, а к 2024 г. до 78 лет ${ }^{18}$, доплаты к пенсии граждане могут зарабатывать физической активностью самостоятельно, не дожидаясь, когда государство, повысившее существенно возраст выхода на заслуженный отдых, всё же выполнит свои обещания.

Таким образом, проведенное исследование позволяет сделать вывод, что с учетом утраченной в процессе проводимых, не всегда продуманных, реформ привычки людей заниматься физической культурой

17 Жителям Узбекистана будут платить за ходьбу пешком. URL: https://news. mail.ru/society/44006304/?frommail=10 (дата обращения: 05.11.2020).

18 Укрепление общественного здоровья : фредер. проект «Демография : национальный проект». 
и спортом население страны, привыкшее, к сожалению, к использованию финансовых понятий, в том числе понятия экономическая выгода, во всех сферах своей жизни, в том числе и к своему здоровью, можно заинтересовать в ведении здорового образа жизни, лишь предусматривая на законодательном уровне различные нормы, стимулирующие граждан в сохранении и укреплении своего здоровья, что абсолютно невозможно без повышения фризической активности каждого.

Перефразируя известную всем народную мудрость: «Спасение утопающих - дело рук самих утопающих", можно категорично утверждать: «Крепкое здоровье зависит от физической активности каждого». Именно поэтому чрезвычайно важно направить усилия как семьи, так гражданского общества и государства на формирование у населения стойкого стремления к здоровому образу жизни, которое невозможно без систематических занятий различными видами фризической активности, в том числе физкультурой и спортом.

\section{Библиографический список}

Кочетова И. С., Усиелелова Н. А. Популяризация спорта среди молодежи Челябинской области // Научное сообщество студентов XXI столетия. Гуманитарные науки : материалы XXVII междунар. студ. науч.-практ. конфр. № 12 (27). Новосибирск, 2014. С. 324-328.

Лесгаббт П. Ф. Избранные труды. М. : ФиС, 1987.

\section{References}

Kochetova I. S., Usselemova N. A. Popularization of sports among the youth of the Chelyabinsk region // Scientific community of students of the XXI century. Humanities: collection of articles on mat. XXVII International Student Scientific and Practical Conference No. 12 (27). Novosibirsk, 2014. P. 324-328.

4. Lesgaft P. F. Selected works. M. : FiS, 1987.

\section{Челябинский государственный уни- верситет}

Соколова Н. В., кандидат юридических наук, доцент кафбедры эконолики отраслей и рьнков Института экономики отраслей, бизнеса и администрирования

E-mail: sokolova45@mail.ru

Шадринский государственный педагогический университет

Черных 3. Н., кандидат педагогических наук, доцент кафбедры теоретических основ фбизического воспитания и безопасности жизнедеятельности

E-mail: z_cherniyh65@mail.ru

\section{Chelyabinsk State University}

Sokolova N. V., Candidate of Legal Sciences, Associate Professor of the Department of Economics of Industries and Markets of the Institute of Economics of Industries, Business and Administration
Shadrinsk State Pedagogical University Chernykh Z. N., Candidate of Pedagogical Sciences, Associate Professor of the Theoretical Foundations of Physical Education and Life Safety Department

E-mail: z_cherniyh65@mail.ru 